
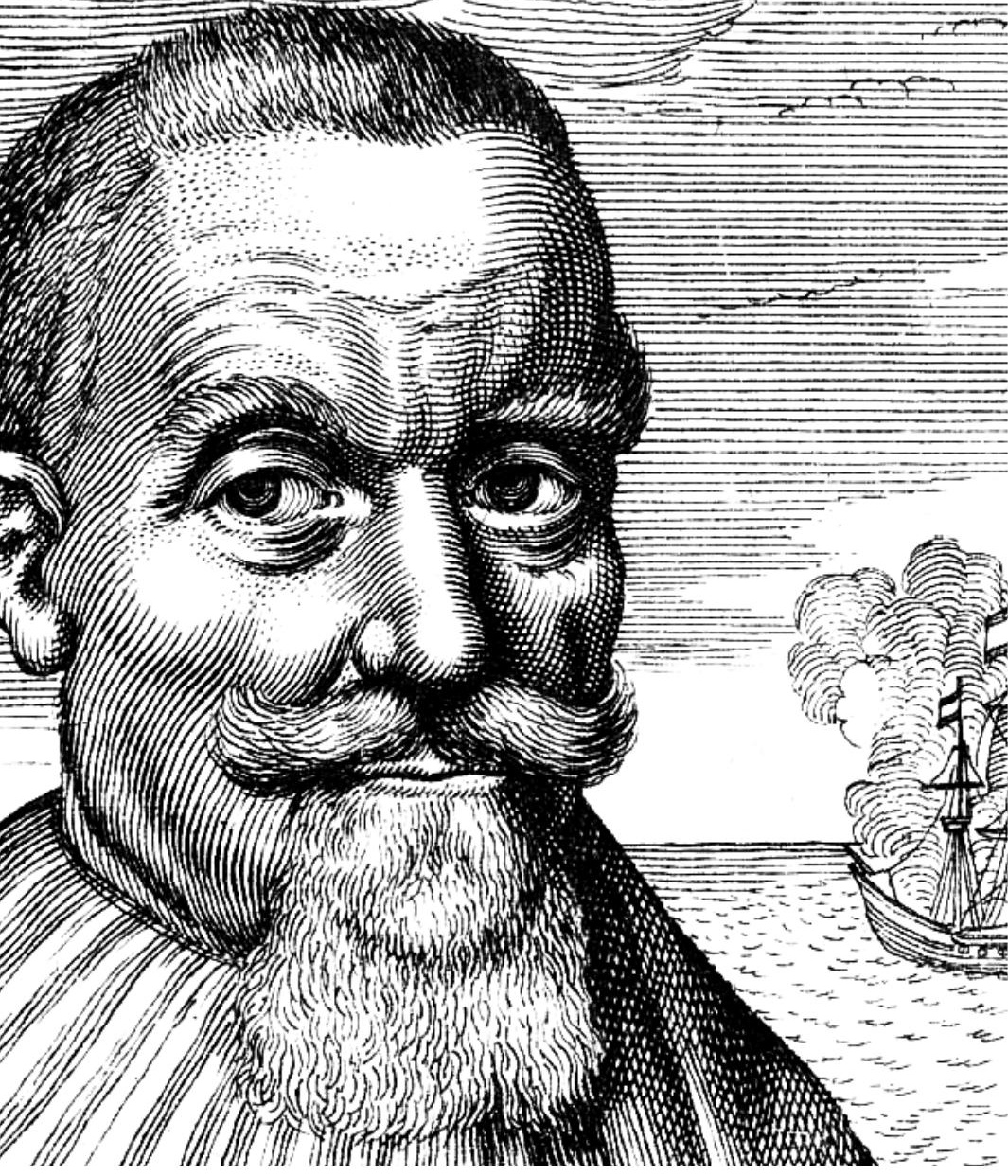

AIBR

Revista de Antropología Iberoamericana

www.aibr.org
Volumen 10

Número 1

Enero - Abril 2015

Pp. 99 - 126

Madrid: Antropólogos

Iberoamericanos en Red.

ISSN: 1695-9752

\section{¿A qué grupo étnico perteneció la misteriosa tribu enoo (Estrecho de Magallanes, 1599)?}

David Williams

Investigador independiente

Recepción: 23.05.2014

Aceptación: 01.03.2015

DOI: DOI: 10.11156/aibr.100106 


\section{RESUMEN:}

En 1599, el marino holandés Oliver van Noort halló en el Estrecho de Magallanes a un grupo de nativos de talla semejante a la de los europeos de la época, con cuerpos y tórax amplios. Los mismos cazaban pingüinos para alimentarse y vestirse, usaban arcos y flechas, vivían en cuevas naturales, y eran presuntamente canoeros.

En un confuso episodio, la mayoría de ellos fueron muertos mediante armas de fuego, cautivándose varios niños. Uno de ellos enseñó a sus captores algunas palabras de su propio idioma, de las que destacamos el autónimo de la tribu: $\langle\text { Enoo }\rangle^{3}$.

Se han realizado varios intentos de identificar la etnia a la cual pertenecían los infortunados nativos, concluyéndose en general que se trataba de alacalufes.

Sobre la base de las palabras rescatadas por Van Noort, y con ayuda de otro documento poco conocido, el autor concluye que los enoo pertenecían a la etnia yamana-también conocida como yaganes- o que eran una tribu mixta yámana-chon. Además, desde que la zona en que fueron hallados los enoo en el siglo XVI es cercana a aquella ocupada por la tribu huemul, mixta fueguino-chon, hallada en el siglo XIX, se plantea la hipótesis de que los segundos pudieran ser descendientes de los primeros.

PALABRAS CLAVE:

Enoo, yamana, yaghanes, Van Noort, Estrecho de Magallanes.

\section{WHICH ETHNIC GROUP DID THE MYSTERIOUS ENOO TRIBE (STRAIT OF MAGELLAN, 1599) BELONG TO?}

\section{ABSTRACT:}

In 1599, in the Strait of Magellan, the Dutch sailor Oliver van Noort found a group of natives of a height similar to that of the Europeans of their time, with wide bodies and thorax. They hunted penguins for eating and dressing, used arrows and bows as weapons, lived in natural caves, and were probably Canoe Indians.

In an unclear episode, most of the natives were shot to death. The sailors captured some children: one of them taught some words of his own language to his captors. From this data we emphasize the self given name of the tribe: $\langle\text { Enoo }\rangle^{4}$. There have been several attempts to identify the ethnicity of the unfortunate natives. Most of the searches have concluded that they were Alacaluf.

On the basis of the analysis of the words collected by Van Noort, and with the help of a less known document, the author concludes that the Enoo were Yamana -also known as Yaghan- or that maybe they were a mixed Yamana-Chon tribe. Besides, owing to the fact that the region in which the Enoo were found in the $16^{\text {th }}$ century is close to that occupied by the Huemul found in the $19^{\text {th }}$ century -a mixed Fueguino-Chon tribe- the author hypothesizes that the latter could have been descendants of the former.

KEY WORDS:

Enoo, Yamana, Yaghans, Van Noort, Srait of Magellan.

AGRADECIMIENTOS:

Prof. Dr. J. Pedro Viegas Barros, del CONICET (Consejo Nacional de Investigaciones Científicas y Técnicas-Argentina), por su apoyo y estímulo para la publicación del presente trabajo.

3. Como Viegas Barros (2001), en el texto utilizo los signos $<y>$ para encerrar entre ambos a determinadas grafías pre-fonológicas.

4. Like Viegas Barros does (2001), in the corpus of the text I use the symbols $<$ and $>$ to enclose between them certain pre- phonological spellings. 


\section{Introducción}

El 25 de noviembre de 1599 el marino holandés Oliver Van Noort halló nativos en la más pequeña de las Islas de los Pingüinos (Pinguynus Eilanden), al oeste-suroeste del cabo Nassau -actual cabo San Vicente, en el estrecho de Magallanes. Ante una provocación mínima, los marinos asesinaron a los hombres y casi todas las mujeres y niños, capturando dos jovencitas y cuatro muchachos. Uno de ellos enseñó a sus captores dieciséis palabras de su idioma, incluyendo dos vocablos importantes etnológicamente: el nombre de la tribu, $<E n o o>$, y el de su país de origen, $<$ Cossi $>$. Van Noort añade una somera descripción física, de la vestimenta y hábitos de la tribu.

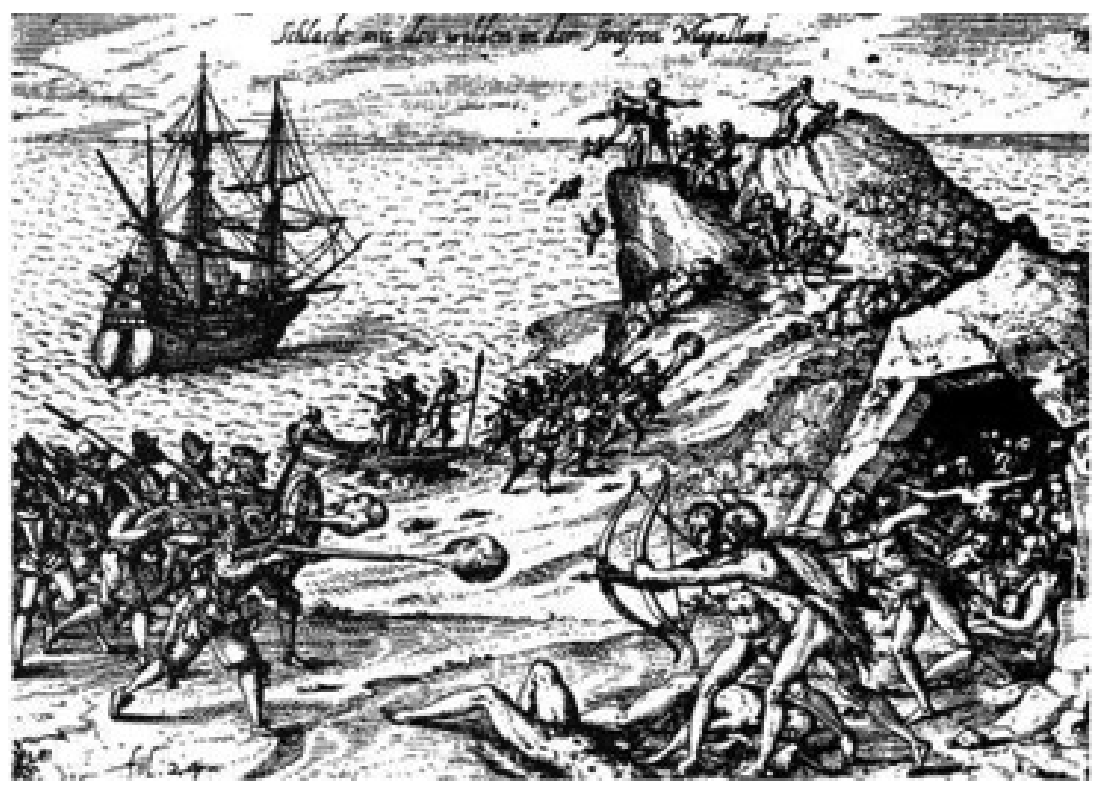

FIGURA 1. Ataque de los holandeses a nativos del Estrecho de Magallanes (Theodore de Bry, 1590-1634). El hecho es erróneamente ubicado en Cabo Orange.

Otro testimonio sobre los enoo ${ }^{3}$ fue dejado por otro holandés, Sebald de Weert (La Harppe, 1820: 213-214; Kerr, 1824: 145), que visitó la isla poco después, el 12 de enero de 1600, hallando a una mujer herida, y

3. Aunque rescatado en época pre-fonológica, adoptamos el gentilicio «enoo» como vocablo constituido en la lengua castellana. Por ello, salvo al citar a Van Noort, lo escribimos sin los signos <>. 
examinando el cadáver de uno de los hombres. No obtuvo datos lingüísticos.

La etnia constituye un misterio antropológico y lingüístico. Hubo varios intentos de identificarlos. A diferencia de Cooper en 1917, LehmannNitsche en 1922, Llarás Samitier en 1967, Clairis en 1977 y 1985, y Martinic Berós en 1989 y 2012, no creo que se autoidentificaran con los alacalufes. En cambio, Gusinde los identificó como yamanas, en 2001 y 2005, Viegas Barros supuso que eran un grupo mixto chon-alacalufe, $\mathrm{y}$ en un trabajo de 2010, Chapman los consideró shelknam.

Creo que intentar una correcta filiación de los enoo -hasta donde pueden clasificarse los grupos humanos- resulta de interés para la etnología y la lingüística de la Patagonia, mejorando nuestro conocimiento del pasado. Mediante el análisis de las palabras y los datos etnológicos documentados, he llegado a conclusiones propias, que me permiten coincidir con Gusinde.

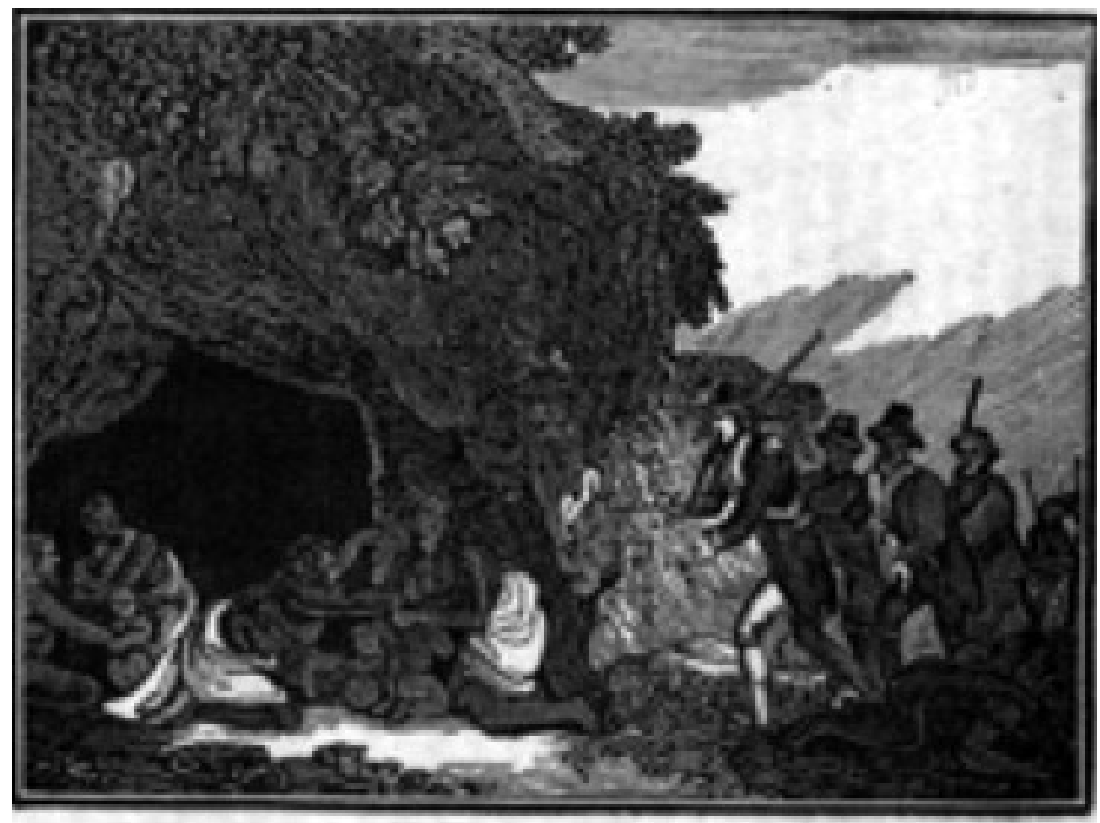

FIGURA 2. Los holandeses ingresando en la cueva de los enoo (Samuel Prior, 1844: lámina entre 52-53). 


\section{Los datos geográficos}

Creo necesario ubicar correctamente las Islas de los Pingüinos de Van Noort (1602: 14-15), identificadas por Cooper $(1917: 6,115)$ y LehmannNitsche (2002: 20) con las actuales islas de Santa Marta -lugar de los hechos- y Santa Magdalena. El examen del mapa de Van Noort (Fig. 3) demuestra que dichos investigadores se hallaban en lo cierto. Actualmente las islas constituyen una de las más importantes pingüineras de Chile.

La correcta localización de las islas es tanto más importante en cuanto que, como observara Michiel van Groesen en 2008 (Martinic Berós, 2012), la edición de De Bry del viaje de Van Noort ubica erróneamente los hechos en Cabo Orange, sin respetar el original del holandés. Ello indujo a varios autores a situarlas allí durante muchos años. En 2012, Martinic Berós mismo refiere haber caído en la trampa en 1997. Otra investigadora engañada es Anne Chapman (2010: 33-34), que sitúa la «Isla Pingüino» a la entrada del estrecho de Magallanes, costa sur, cerca del Cabo Orange -actual Punta Catalina- atribuyendo a los enoo ser de etnia shelknam. En cambio, en el siglo XIX, Fitz Roy señalaba que las Islas de los Pingüinos se hallaban cerca de la Isla Elizabeth, lo que prueba que las conocía perfectamente.

Lo cierto es que, por hallarse las islas en pleno territorio históricamente alacaluf, la mayoría de los investigadores, algunos añadiendo escasas evidencias lingüísticas, han supuesto que los enoo pertenecían a dicha etnia.

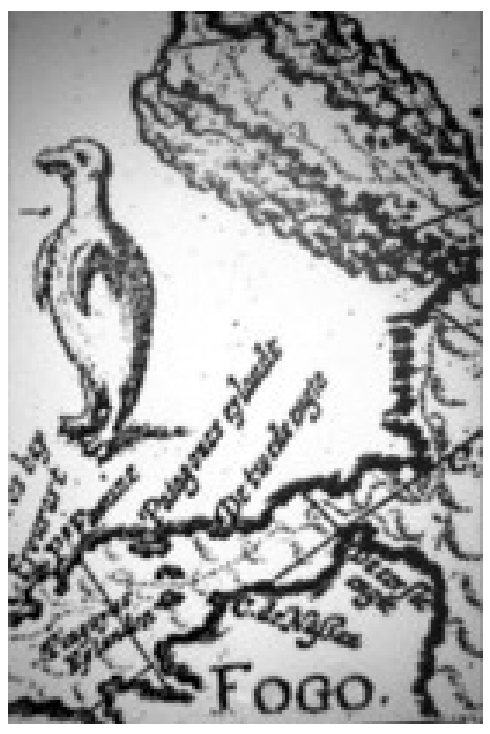

FIGURA 3. Fragmento del mapa Stretum Magallanicum, in quod Olivier $d$. Noort generalis navirum devenit quintodic Novembris An. 1599 hinc et in Mare del Zur naviss.dic. February An. 1600 usque Conceptionta aurc abundantem (Van Noort, 1602: 19). Se ven las Islas Pingüino al este del Cabo Nassau, actual San Vicente. Confirmamos que la menor de ellas -<Talcke $>$ según los enoo- es la actual Santa Marta, y que la mayor $-<$ Castemme $>$ - es Santa Magdalena. Patagones Eynlandt o Isla de los Patagones es la actual Isla Isabel. 


\section{Datos etnológicos dejados por los holandeses}

Se resumen en la Tabla 1.

Ninguno menciona canoas, pero aunque no las hubiera en la isla, probablemente habían sido llevados a ella por otros nativos, integrantes o no de la tribu, que habrían regresado a tierra.

Con respecto a la talla de los enoo, si era semejante a la de los holandeses de la época, aproximadamente 1,60 m (Martínez Carrión, 2011), era unos $20 \mathrm{~cm}$ menor que la de los pueblos chon. Apenas algo mayor que el promedio de los yamana del siglo XIX ${ }^{4}, 1,55 \mathrm{~m}$ según E.L. Bridges (2005: 57), o 1,58 para los varones y 1,47 para las mujeres según Latcham (1928). Aunque Orquera y Piana en 1999 (Canclini, 2007: 17), promediando informes de quince autores, anotan 1,57-1,61 en hombres y 1,47-1,55 en mujeres.

Además, los tórax «altos y largos» descriptos por Van Noort son típicos de los fueguinos, especialmente de los yamana. Escribe Fitz Roy que medían entre 1,45 y 1,65 m, pero que sus torsos parecían de hombres de 1, $80 \mathrm{~m}$, siendo el tronco grande con respecto a los miembros delgados y curvos. Bove (2005: 114) anota: "Las piernas y los brazos son de una flaqueza sorprendente y uno se admira cómo aquéllos pueden sostener una cabeza tan voluminosa y un pecho tan desarrollado».

Según Gusinde (1951: 43-44):

Son una raza de baja estatura; los hombres tienen por término medio una estatura de $160 \mathrm{cms}$ y las mujeres unos $148 \mathrm{cms}[\ldots]$ predomina en ellos una singular proporción entre el desarrollo del tronco $\mathrm{v}$ las extremidades: las piernas son relativamente cortas en relación a su gran tronco, y los brazos resultan siempre demasiado largos en proporción al tamaño del cuerpo. Las mujeres de mediana edad, mucho más que los hombres, presentan los hombros muy vigorosos, así como la parte superior del cuerpo; la musculatura del pecho se les desarrolla extraordinariamente. Su tronco es enormemente ancho.

Curiosamente, Schapenham (Gallez, 2007), que conoció a los yamana en 1624 -apenas un cuarto de siglo más tarde que sus compatriotas Van Noort y De Weert hallaran a los enoo-, escribe sobre los primeros: «Su figura es apuesta, sus miembros bien proporcionados...», no condiciendo con lo que los cronistas posteriores escribieron, ni con las fotos y dibujos que nos han llegado desde el siglo XIX y comienzos del XX. Schapenham

4. Los holandeses, hoy uno de los pueblos más altos de Europa, fueron de los bajos -1, 64 $\mathrm{m}$ en 1829; en $18561,62 \mathrm{~m}$ en zonas rurales, y 1,58 $\mathrm{m}$ en la ciudad (Drukker y Tassenaar, 2000: 83, figs. 1 y 2). 


$\begin{array}{lll} & \text { Oliver Van Noort, } & \text { Sebald de Weert, 12/01/1600 } \\ \text { 25/11/1599 (1602: 14 y } & \text { (La Harppe, 1820: 213-214; } \\ \text { OBSERVADOR } & \text { Kerr, 1824: 145). } \\ & \text { Semejante a la de } & \begin{array}{l}\text { Conoció a una mujer alta } \\ \text { y bien formada. }\end{array} \\ \text { ESTATURA } & \begin{array}{l}\text { los holandeses, aunque } \\ \text { con tórax altos y largos. }\end{array} & \begin{array}{l}\text { Examinó el cadáver } \\ \text { de un hombre, sin describir } \\ \text { su estatura }\end{array} \\ & \text { Cortos (mujeres) } & \text { Cortos (mujer). } \\ \text { CABELLOS } & \text { Pendientes por delante } & \text { Largos, con tocado de plumas } \\ & \text { de la frente (hombres). } & \text { (hombre). }\end{array}$

PINTURA FACIAL Rostros pintados de colores. Rostros pintados.

$\begin{array}{lll} & \begin{array}{l}\text { Mantos de pieles de } \\ \text { pingüinos, excelente }\end{array} & \begin{array}{l}\text { Mujer: manto hasta las rodillas } \\ \text { de pieles de animales }\end{array} \\ \text { VESTIMENTA } & \begin{array}{l}\text { costura. } \\ \text { Hombres: desnudos, pene }\end{array} & \begin{array}{l}\text { y aves cosidas; taparrabo } \\ \text { de piel. }\end{array} \\ & \begin{array}{l}\text { atado a la cintura. } \\ \text { Mujeres: taparrabo de pieles. }\end{array} & \text { Hombre: adornos de plumas. } \\ \text { ARMAS } & \text { Flechas. } & \begin{array}{l}\text { Arcos y flechas de fina punta } \\ \text { de pedernal duro. }\end{array}\end{array}$

\begin{tabular}{|c|c|c|}
\hline \multirow{2}{*}{ ALIMENTOS } & $\begin{array}{l}\text { Pingüinos de la isla, } \\
\text { y avestruces de tierra firme } \\
\text { (¿Península de Brunswick?). }\end{array}$ & \\
\hline & $\begin{array}{l}\text { "Creemos que todos ellos } \\
\text { son devoradores de carne } \\
\text { humana*». }\end{array}$ & \\
\hline VIVIENDA & $\begin{array}{l}\text { Cuevas (tal vez } \\
\text { circunstancial). }\end{array}$ & $\begin{array}{l}\text { La mujer se refugiaba en una } \\
\text { caverna. }\end{array}$ \\
\hline $\begin{array}{l}\text { TIERRA DE } \\
\text { ORIGEN }\end{array}$ & $\begin{array}{l}\text { «En nuestra opinión habían } \\
\text { venido a la isla desde tierra } \\
\text { firme }[. . .] \text {, distante de allí } \\
\text { casi media legua» }\end{array}$ & $\begin{array}{l}\text { La mujer solicitaba ser } \\
\text { trasladada a la península } \\
\text { de Brunswick. }\end{array}$ \\
\hline
\end{tabular}

TABLA 1. Comparación de los datos etnológicos de Van Noort con los de De Weert.

*. Opinión extendida luego a todos los canoeros fueguinos, de la que nadie halló jamás pruebas en tiempos históricos, y desmentida explícitamente por varios autores que los conocieron. 
añade que su altura era semejante a la de los europeos, confirmando que los holandeses del primer cuarto del siglo XVII eran de igual talla que los yamana. Ello apoya la idea de que a tal etnia, y no a los chon-de talla mucho más elevada- pertenecían los enoo.

Es decir, físicamente, los enoo eran más semejantes a los fuéguidos que a los pámpidos, aunque la mujer «alta y bien formada» vista por De Weert pudo ser pámpida o metamórfica pámpido-fuéguida.

Sobre arreglo personal y vestimenta, el cabello largo y por delante de la frente en hombres es característica fueguina, no así el cabello corto en mujeres, tampoco típico de pámpidos, pero aplicable a los alacalufes. La escueta descripción no permite hacer suposiciones en lo tocante a pintura facial. Los tocados de plumas eran raros a comienzos del siglo XX entre los yamana, pero ocasionalmente los usaban.

Los mantos de pieles de pingüinos y otras aves, la desnudez de los hombres, y el taparrabos de piel de las mujeres, son típicos de los fuéguidos. Pero entre ellos los cueros no eran de excelente costura como los observados por ambos capitanes. Ni llegaban a las rodillas como los de la mujer que vio De Weert: generalmente cubrían los hombros y el pecho hasta la cintura -lo que vuelve a hacernos pensar en una mujer de etnia pámpida.

Aunque no era frecuente entre los yamana del siglo XIX, el uso de arcos y flechas está ampliamente documentado. Schapenham los menciona en 1624 , en lo que hasta ahora se consideraba la primera descripción del pueblo yamana.

Así, la mayor parte de las pruebas étnicas apuntan a que los enoo eran fuéguidos, aunque algunas características de la mujer sobreviviente sugerirían clasificarla como pámpida -tal vez lo fuera y conviviera con los enoo.

\section{Datos lingüísticos de Van Noort e hipótesis del autor del presente trabajo}

En mi opinión, nadie ha hallado una relación convincente entre la lengua de los enoo y las lenguas alacalufes. No alcanza la asociación de Lehman-Nitsche (2002: 20-21) de un vocablo enoo con otro alacaluf; ni la de Clairis (1977 y 1985), que ya estudiaremos. Más sustento tendría la teoría de Viegas Barros (2001: 1-4, y 2005: 68), que presenta coherentes analogías con las lenguas chon, y unas pocas con las alacalufes, concluyendo que la lengua de los enoo era mixta chon-alacalufe.

Por mi parte, creo que, pese a hallarse bastante alejados del territorio de los yamana históricos, los enoo de Van Noort eran una parcialidad 
yamana. O pre-yamana, desde que no utilizaban, cuando menos, no en primera acepción, el autónimo yamana. Así, aunque no fundamentó su idea, Gusinde habría acertado al clasificar como yamana a los enoo.

Es que suele olvidarse una regla básica de la etnología: para traducir los autónimos o gentilicios auto-aplicados de etnias y culturas llamadas primitivas, debe pensarse en significados en que ellas sean el centro del mundo, del Universo, de la historia, las primeras, originales o elegidas. Usualmente el vocablo significa «los hombres», "la gente», distinguiéndolos de otras etnias, que quedan más abajo en la escala: el centro de referencia del mundo es su propia gente, grupo, cultura, país; son los «Hombres (verdaderos)», los «Hijos de Dios», «El Pueblo Elegido», etc.

Bridges (2001: 109) dice sobre los yamana: «No tienen un nombre especial para si mismos, pero como muchas otras razas primitivas, se llaman a si mismos yamana (o sea 'hombre') y a su lengua yaman' hasha (o sea 'voz humana')', como si ellos fueran la raza humana de forma especial»" Gusinde (1951: 118): "Se denominan a si mismos 'Yamanas', en el sentido de 'nosotros' y 'nuestro pueblo'». Desde luego, yamana no es igual a $<$ Enoo $>$ - aunque podría suponerse que la primera palabra podría contener a la segunda en su parte final, -ana:

1. Pero existe en yamana-hasha una palabra del mismo significado que sí se asemeja a $\langle$ Enoo $>$ : $\langle 0 n a\rangle=$ «hombre», según Beauvoir (1998: 15), <won>= «hombre», según Bridges (Brinton, 1892: $87)^{7}$.

2. Vocablo que podría tener un cognado en <ûöna >= «llegar a ser un hombre. Crecer hasta ser hombre» (Bridges, 1987: 70, trad. propia). Muchos lo confunden con el gentilicio <Oensmen $>$ de Fitz Roy y Darwin, <Owenamen $>/<$ Owent-men $>=$ «indios de a pie» de

5. <haša > "voz, lengua, palabras emitidas, el habla. Respira(ndo). Llanto, emisión» (Bridges, 1987: 268). Modernamente, la lengua ha recibido el nombre de háusi kutə (Hidalgo et al., 1996: 289), es decir, «(mi) tierra- lengua», o sea, «la lengua de mi tierra».

6. El término <Yahgan> fue creado por Thomas Bridges (1987 y 2001: 109) a partir de un sitio llamado Yagha -probablemente la palabra <shaga $/<y a g a\rangle=$ "estrecho o canal», que como topónimo aislado se aplicaba al estrecho de Murray. Bridges confirma que se auto-denominaban yamana. Clairis (Fabre, 2005: 1; Viegas Barros, 2005: 33, n. 3 y 1985) refiere que las últimas hablantes de la lengua preferían ser llamadas yaganes, porque el significado de yamana es el de «hombre/s», excluyendo a las mujeres. Probablemente, la transculturación y prejuicios de origen moderno, motivaran la preferencia del gentilicio inventado por Bridges. Chapman (2010: xxii) adopta una solución intermedia, tratando de adecuarse tanto a ambas posturas, y utiliza indistintamente ambos gentilicios

7. En el Diccionario de Bridges (1987: 273, traducción propia) hallamos <haua-ûan>= «este hombre»-en realidad «mi hombre», es decir, «mi esposo», de donde <-ûan> sería efectivamente «hombre», documentado como<ûa> en páginas anteriores (1987: 66). 
Bridges (2001: 15 y 149), que, creo, tiene otro significado -no es este el espacio para discutirlo- y del cual surge el gentilicio «onas». Que no es la misma palabra que $\langle$ Enoo $\rangle$, ni que $\langle$ ona $\rangle \mid\langle$ won $\rangle=$ «hombre».

3. Creo que esta última palabra está incluida en el topónimo con que los yamana denominaban a la isla grande de Tierra del Fuego: $<$ Onaishin> y variantes, generalmente interpretado como "Tierra de los onas». Creo que difícilmente un pueblo de los llamados primitivos adjudicaría su propia tierra a otra etnia. En realidad el topónimo debe estar compuesto de $\langle$ Ona $\rangle=$ «hombre» + <uši $(n)\rangle=$ «tierra, territorio». Tendría así razón Brinton (1892: 250, trad. propia) que documentaba <oneçin $>=$ «tierra de hombres»; Bridges (1987: 265, traducción propia) deja una variante, $<$ Hannūsi- $(n)>=$ «mi país, mi tierra (usado especificamente)».

4. También aparecería en <Onashaga> y variantes, el nombre del Canal de Beagle según autores varios, que significaría "Canal de los Hombres». Y hay más ejemplos, pero basta con estos. Si estoy en lo cierto, los enoo serían un pueblo yamana -o pre-yamana.

A partir de esta observación he realizado otras comparaciones entre la lengua de los enoo y el yamana-hasha -o haushi-kuta, como se llamó más modernamente a la lengua. Para estudiarlas, divido a las dieciséis palabras documentadas en tres grupos: A, altamente sugestivas de una identidad entre ambas lenguas; B, moderadamente sugestivas; C, poco sugestivas; y D, no sugestivas -aunque desde luego no descartan tal identidad. Puede aceptarse cierta laxitud en los grupos, si es que se hallan otros vocablos yamana comparables con los de los enoo.

\section{Grupo A: altamente sugestivas:}

- $\quad<$ Enoo $>$ : autónimo o gentilicio auto-aplicado -e.g. la ya mencionada palabra <ona $>$ (Bridges), <won $>$ (Beauvoir) $=$ «hombre» en lengua yamana.

- <Cosfi>: "país de los Enoo». Compárese con los vocablos del yamana-hasha:

1. <o'she>= «tierra» (Parker King y Fitz Roy, 1839, Vol. II, Appendix: 137, traducción propia), <usi>= «tierra» (Bove, 2005: 143), documenta $\langle$ usi $(n)\rangle=$ «territorio. Tierra (no isla). La Tierra. Tierra, país, distrito, lugar» (Bridges, 1987: 103, traducción propia),<usi $>=$ "país» (Bridges, 2001: 150). 
2. <usi>= "gente, aldea» (Coiazzi, 1999: 126).

3. <yuscha $>=\left\langle\operatorname{costa}^{8}{ }^{8}\right.$ (Coiazzi, 1999: 126), <yusha> (Bridges, 2001: 150), <ju-sa $>=$ «playa, margen» (Bove, 2005: 144). <Onayuscha $>=$ "costa de Ona» (Bridges, 2001: 158) -supongo que sería "costa del/de los Hombre/s».

4. Más semejante es la palabra xáuši = «tierra», en <háusi kutə> (Hidalgo; Schiappacasse; Niemeyer; Aldunate y Mege, 1996: 289) = "(la) lengua (de mi) tierra», donde <guta $>=$ «lengua, habla, palabra, palabra pronunciable» (Bridges, 1987: 255, trad. propia). Y <xáuši correspondería al <Cosji> de Van Noort: suponemos que a su vez se compone de <haua $>=$ «mi, mío» (Bridges, 1987: 272) y <uši $(n)>=$ "tierra, territorio, país», es decir, <xawa uši $(\mathrm{n})>=$ «mi tierra»-ver Bridges (1987: 273), <hau'isin>= «mi país, mi lugar».

5. <kössi- $f>1<k o ̈ s s i-p u n>=$ "extremo más oriental de la costa o borde», $<k u \overline{s i}-f>1<k u \overline{s i}$-pun>= "cualquier extremidad de tierra o punta yaciendo o extendiéndose al este, extremidad más oriental de cualquier tierra» (Bridges, 1987: 187, trad. propia): probablemente, aquí <kūsi> ha sufrido una lexicalización, y la palabra aglutinada que originalmente significaba «mi tierra» pasó a significar el genérico «tierra»-mecanismo frecuente en las leguas llamadas primitivas ${ }^{9}$. El resto de las palabras parece aglutinar los vocablos $<y i f>=$ "adjetivo. Elevándose, terminando en una cresta o borde angosto, estrecho, filoso, agudo, delgado" y <yīpun>= "el borde de cualquier colina, banco, $u$ otro objeto» (Bridges, 1987: 636 y 651, trad. propia).

Así, la palabra $<\operatorname{Cos}$ /i $>$ habría sido correctamente transliterada por Van Noort. Correspondería a $<k o ̈ s s i>0<$ o ūsi $>$ de Bridges y a <háusi $>$ de Hidalgo et al.= «(mi) tierra» en yamana-hasha.

- $\quad$ <Tiremenen>: gigantes de 10-12 pies de altura, habitantes de un país llamado <Coin>, "que vienen a hacer la guerra a las otras estirpes, reprochándoles ser comedores de avestruces».

8. <yuscha>: según convención de Coiazzi (1999: 11), su grupo «sch» se pronuncia con fonética alemana, es decir, «š». Así, fonéticamente, la palabra sería yuša.

9. Lucien Lévy-Bruhl (1986: 57-69, 95 y 126-129) estudia este mecanismo desde la etnología, señalado por otros desde la lingüística. La explicación es demasiado extensa. En las lenguas llamadas primitivas algunos vocablos solo pueden expresarse asociados al pronombre posesivo. 
Compárese con:

1. <etalum ona $>=$ "ona del este», nombre yámana de los háush (Bridges, 2005: 56), <italum-ūa>= «hombre del este», <italumąala $>=$ «hombres de este» (Bridges, 1987: 3-4, trad. propia).

2. Donde <italitu>= «este» (Bove, 2005: 144); <italum>= «desde el este, desde allí si (es) desde el este, desde abajo como si fuera desde la parte más abajo, la más alta de una colina»; <ita>= "adv. este, oriental. Perteneciente al este. Allí, allí abajo hacia el este»; <itaūa $>=$ «un hombre oriental, un hombre del este» (Bridges, 1987: 3 y 4, trad. propia). Es decir, <etalum ona> de Lucas Bridges sería ətalum-ona = "oriente-hombre(s)», o sea, «hombres del este $u$ oriente» ${ }^{10}$.

Y nótese que:

3. En el vocablo <Tiremenen $>$ de Van Noort, la fracción <menen> habría sufrido una asimilación al vocablo holandés mannen= «hombres», semejante a la que sufriría en el siglo XIX su equivalente $<$ men $>$ de Fitz Roy y Darwin en $<$ Oens-men $>$ y $<$ Coin-men $>$ $\mathrm{y}<$ Owenamen $>/<$ Owent-men $>$ de Bridges (2001: 15 y 149), equiparada al vocablo inglés men $=$ "hombres», lo que explica la adición de las terminaciones $-e n$ del primer caso y $-n$ del segundo ${ }^{11}$.

4. Según el propio Bridges (1987: 315, trad. propia): <möni>= «ser, especialmente dicho sobre personas o cosas que se paran; estar vivo, esperar, estar esperando, parar, pararse (firme), detenerse, quedarse, demorarse, vivir o morar en un sitio; ser o continuar, ser por un tiempo, existir, estar vivo, soplar, ser (dicho de una brisa)».

De donde el gentilicio en cuestión podría recomponerse como ìtalumməni= «ser vivo (bipedo, que se para) del este». Esta palabra -məni se conserva en varios gentilicios yamana: el que nos ocupa es un ejemplo. Así, las formas inglesas serían correctas, y no la holandesa recogida entre los enoo.

- $\quad<$ Coin $>^{12}$ : tierra de los $<$ Tiremenen $>$.

10. Según ya sospechaba Cooper (1917: 48): «El muchacho capturado por Van Noort posiblemente se refería a los onas cuando

11. Error extendido a la traducción que Canclini realiza de T. Bridges (2001: 149), en donde <Owent-men > es traducido como «hombres de Owent».

12. Cooper (1917: 114 y 115): asocia a <Coin> con un hipotético <Choin>, en obvia referencia a los chonos. Consideramos no viable esta idea. 
1. Nos concierne aquí uno de dos gentilicios con que el yamana Orundellico, más conocido como Jemmy Button, denominaba a los onas según Fitz Roy y Darwin: $<$ Coin men $\rangle^{13}$.

2. Ya Fitz Roy (Parker King y Fitz Roy, 1839, II: 206, traducción propia) asociaba al país <Koin> de Van Noort con los <Coin-men $>$ de Orundellico, que habitaban en "el cuarto noreste de la isla de Tierra del Fuego [...] pasando las montañas en el lado norte del Canal de Beagle», y cada otoño cruzaban las montañas, atacando a los alacalufes, quitándoles mujeres, armas, perros, etc. Su localización al noreste permitiría identificarlos como háush o mánekenk, una etnia ona, y coincide con la traducción de <italum-ona> como «hombres del este». Además, según L. Bridges (2005: 56), los háush "[...] eran conocidos por los yaganes como etalum ona (ona del este)».

Probablemente, los <Tirimenen> de <Koin> eran los háush/mánekenk. Ello confirmaría indirectamente que los enoo eran un pueblo yamana, originario del sur de Tierra del Fuego, y no del noreste, donde los hallara Van Noort; de otra forma los <Tirimenen $>$ se hubieran ubicado muy al sureste de ellos -aunque nada quita que la etimología del gentilicio hubiera sido olvidada por los enoo.

¿Y qué significa <Koin-men>? Hay vocablos del yamana-hasha semejantes a este topónimo -e.g. (Bridges, 1987: 204, 205, trad. propia).

1. <kūāna > = «pasar yendo o viniendo al oeste»; <kūön-a>= «ir o venir desde la puerta desde adentro o desde cualquier lugar en dirección oeste y wuna» ${ }^{14} ;<$ <ūāna>= "pasar yendo o viniendo al oeste, pasar yendo a la entrada, pasar yendo al oeste, etc.»; <kūu-onigū $>=\langle d e-$ jar ir al oeste y golpear. Ir hacia o venir del oeste»; <kūu-önigū $>=$ "permitir que vaya hacia el oeste y golpear»; <kūön-igu> = "golpear como el mar a un barco desde el este; expuesto a los vientos del este como una costa oriental abierta; golpear o chocar una ventisca del este contra una costa expuesta. Ir hacia el oeste y golpear»; <Kūu-unusiū >= «ir o venir hacia el oeste y alli avergonzar».

2. Küön-igatun $>=$ «la costa o playa oeste de cualquier bahía, estrecho o puerto».

13. El otro gentilicio, sinónimo de $<$ Coin-men $>$, era $<$ Oens-men $>$, origen del gentilicio «ona(s)», como mencioné antes.

14. <wuna $>=$ "ladrar como un perro, zorro, o lobo. Reprender, retar, censurar, regañar, hablar enojado a una persona, contender con palabras» (Bridges, 1987: 633, trad. propia). 
3. <Kūu-unna > = «ir o venir, i.e. caminar yendo».

Por otro lado, vimos ya que <möni $>=$ «ser, estar vivo, esperar», etc. -ver párrafos anteriores. Podríamos recomponer <Coin-men> como kəon-a məni, que podría significar «seres vivos que vienen del este al oeste y golpean»-o, simplemente, «seres del este».

\section{Grupo B: moderadamente sugestivas:}

- $\quad<$ Kemenetes $>$ : habitantes del país <Karay>. Ver Bridges (1987: 172, trad. propia):

1. <kinnum-ū-mūtū>, <kinnum-ū-möni>, <kinnum-ania = "ser manso, no sospechoso, etc. No estar sospechando nada malo o bueno, quedarse de la misma manera, mentir, o estar mintiendo» (1987: 181);

2. <kömöni>= «levantarse de dormir y parase, erguirse, ir o venir arriba como en una colina y pararse. Levantarse y pararse en la cima, prefijo verbal ir o venir arriba. Intransitivo ser, soplar como un viento del este. Ser un viento del este, soplar hacia el oeste. Elevarse alto como el sol en un día de verano. Estar estacionario en el oeste, etc»;

3. <kömū-könata>= "extenderse, ir o venir un largo camino hacia o desde el oeste, o, más adelante» (1987: 258);

4. <kömo-či>= "entrar en dirección oeste, ir o venir del este y entrar»;

5. <kömöni> = «levantarse de dormir y parase, erguirse, ir o venir arriba como en una colina y pararse. Levantarse y pararse en la cima, prefijo verbal ir o venir arriba. Intransitivo ser, soplar como un viento del este. Ser un viento del este, soplar hacia el oeste. Elevarse alto como el sol en un día de verano. Estar estacionario en el oeste, etc»;

6. <gumm-mütu>= «vivir de moluscos, comerlos, estar comiéndolos, sentarse o estar sentado comiéndolos».

Denominar a una etnia vecina como «mansos», o «los que suben desde el este hacia el oeste», o "comedores de moluscos» sería algo típico, pues los gentilicios aplicados a parcialidades distintas de la propia solían ser apodos.

- $\quad<$ Kennekas >: habitantes del país <Karamai> -e.g.: 
1. <hanū-ka>= «hacia la costa, hacia la tierra, costa, orillalmi país, mi tierra (usado especificamente)»(Bridges, 1987: 265, trad. propia);

2. <hannuwa>= «mis compatriotas (generalmente en sentido de reproche)» (1987: 266);

3. <hinnakan $>=$ «borde, margen, costa del mar, laguna, río. Posición en o cerca del agua. Cerca del margen del agua» (1987: 267);

4. <hāni>= «el viento norte»;

5. <kūāna>= "pasar yendo o viniendo al oeste, pasar yendo hacia la puerta, etc.» (1987: 204 y 205); <kūu-onigū>= «dejar ir al oeste y golpear. Ir hacia o venir del oeste» (1987: 182).

6. <köna>= "estar en el agua como cualquier objeto vivo o muerto - estar en el agua como una canoa, bote, barco o isla. Estar en o sobre cualquier objeto flotante, estar, quedarse, ser a bordo, etc.» (1987: 182);

7. <köni>= "profundo, lejos, distante, muy alto, muy profundo, muy ancho, muy lejos (apartado)» (1987: 182);

8. <könĵi>= «sur, al sur»; <könji-ku>= «al oeste de aquello» (1987: 183);

9. <könain-āgū>= «ir o viajar en la canoa de uno mismo».

10. En otra fuente: <hanna>= «terreno» (Coiazzi, 1999: 126).

- Terminaciones de algunos gentilicios: <-eka $>$ en $<k e n n e k a>$; <-ike> en $<$ karaike $>$; <-ete $>$ en $<$ kemenete $>$.

E.g. para los dos primeros, incluso para el tercero si admitimos un error de transcripción de «t» por «k»:

1. $\quad<a \overline{k i}>=$ "él, ella, ello, algo, usado en forma indefinida, como cuando uno no puede recordar el nombre de la cosa o persona, como cuando decimos ¿iSr..., cómo se llamaba?»;

2. <āki(n)>: cuando va sufijado a un adjetivo significa «ese, eso que es, él quien es»; sufijado a sustantivo es «con, por medio de»; sufijado a un verbo es "uno, él, ella, ello, que es, tal como es»; sufijado a pronombre en -pai es "perteneciente a» (Bridges, 1987: 55, trad. propia $)^{15}$.

15. Bridges da ejemplos para cada caso: e,g. <luš-aki>= "el rojo»; <ānan-āki>= "con, en o por la canoa»; <makurū-āki>= «lo que es amado, gustado, sea persona o cosa»; <kötūpai-āki>= 
Para el tercero, si no hay error de transcripción:

3. Bridges (1987: 4, trad. propia) anota <ītū>= «adv. de dirección (opuesto a <inū>). Hacia el este, al este. Abajo, como colina abajo».

Así, por_ejemplo, <Kennekas > podría recomponerse como hannu-əki= «los costeros, los de la orilla», tal vez otra tribu yamana o los alacalufes, o como Koin-əki= «los que vienen o van al oeste (desde el este)»-ver Bridges (1987: 55).

- <Morine >: país de los <Karaikes >, erróneamente transcripto $<$ Marina $>$ por Cooper (1917: 115), e.g.:

1. <mara $>=$ "agudo, como una punta; montôno montículo» (Bridges, 1987: XVII y XVIII, trad, propia);

2. <möra>= «la punta como de aguja, lezna, etc. Puntudo, agudo como una aguja o lezna. Picudo, dentado";

3. <möran-ia>= «ser puntudo, yacer como cualquier cosa puntuda sobre la tierra. Un toldo de palos doblados y ramas entrelazadas. Construir tal choza o enramada» ${ }^{16}$ (1987: 316).

4. Con respecto a la terminación <-ine $>$ en dicho topónimo $<$ Morine $>$, ver Bridges (1987: 3, trad. propia), <inū>>= «adv. de dirección. Arriba, hacia arriba. Hacia el oeste, arriba al oeste, arriba en una colina».

Es decir, <Morine > podría ser un país montañoso al oeste, para llegar al cual había que ascender en dicha dirección: e.g. las montañas de Tierra del Fuego corren aproximadamente de oeste a este, con leve desviación norte-sur.

- $\quad<$ Compogre>: pingüino; <Oripogre >: pájaro diferente del pingüino, manto hecho con su piel, e.g.:

1. <apa-wôra>= "vincha hecha con pequeñas plumas unidas estrechamente una con otra» (Bridges, 1987: 27); <amarapawa $>=$ «tocado o vincha de guanaco»; <hapawára>= «vincha de plumas de cigüeña» ${ }_{-}^{17}$, apæwaıa= «tocado de plumas» (Aguīlera, 2000: 237).

«persona o cosa que pertenece a tal lugar o persona, o por tal razón», y otros ejemplos.

16. De allí probablemente el nombre de una choza ceremonial de los yamana, llamada $<$ murana>, según Bridges (2001: 18).

17. O <hapawúrrh $>$ en dialecto del este. Comparar con $<$ wurrsch $>=$ «correa de piel de lobo 
2. <páwa $>=$ «polainas» (Lothrop, 1928: 124 y 217, trad. propia).

La palabra -pawa, componente común de los vocablos mencionados, indicaría partes del vestido confeccionadas con cuero o plumas ${ }^{18}$.

\section{Grupo C: poco sugestivas:}

- $\quad<$ Karaikes $>$ : habitantes de $<$ Morine $>-$ e.g.:

1. <kušiu-āki>= «persona o cosa no gustada, no amada» (Bridges, 1987: 221, trad. propia);

2. <köči-yella-āki>= "aquél o aquello más occidental, como la isla más occidental de una cadena de islas, la última de tres esposas, o sea aquella cuyo sitio es el más alejado de la puerta de la choza» (1987: 173), en donde reconocemos:

a. $\quad$ el sufijo <āki(n)>, ya mencionado;

b. la palabra <kössi-f>= «el punto o costa más occidental» (1987: 187);

c. $\quad<y e l l a>=$ "partir de, irse de, desertar, abandonar, dejar atrás, afijo a verbos» (1987: 647 y 648).

De donde <Käraikes> podría ser *karay- āki= «los que pertenecen a Karay, hacen Karay, o son Karay». Nos preguntamos si no será un error de transcripción que-los $<$ Kemenetes $>$ habitaban $<$ Karay $>$, que tal vez sea la tierra de los $<$ Karaikes $>$ o karay-āki.

- <Cossoni>: animales, "ciervos», según Van Noort (1602: 14 y 15, traducción propia) -seguramente huemules, y no guanacos, como cree Cooper (1917: 115)- aunque como los guanacos eran desconocidos para los holandeses, «ciervo» pudo ser una traducción aproximada ${ }^{19}-$ e.g.:

1. <Ushwámi >= "tendón de guanaco», <Wurrsch>= "correa de piel de lobo marino» (Lothrop, 1928:144, 147 y 217, traducción propia), ušuámi = "hilo (tradicional, hecho de nervio de ballena o guanaco)» (Hidalgo et al., 1996: 291);

marino» (Lothrop, 1928: 144 y 147, trad, propia).

18. Pawa: tal vez la misma palabra, o variante de la que Bridges (1987: 628, trad. propia) documentara como <wöhwa $>=$ "piel del macho del cauquén marino, desplumado y usado como yesca».

19. Vernazani (2007: 49) interpreta que se trata de venados o vicuñas, siendo corregido por De Angelis, que anota que en lugar de «vicuñas» debe decir «guanacos». 
2. <wæsāna>= «ratón» (Bridges, 1987: 627); <woesána>= «ratón» (Aguilera, 2000: 236);

3. <kaiyenuš > = "pichones de gaviota blanca común antes de tener plumaje blanco, los pichones imperfectos o menores de un año de la gaviota común negra de alas blancas» (Bridges, 1987: 169 y 170, trad. propia).

Ello podría implicar un error entre <cassoni $>$ y <oripogre $>$, correspondiendo respectivamente a <kaiyenuš $>=$ "pichón de gaviota» y amarapawa = "guanaco (vincha de)». Así, <cossoni serían las otras aves de cuya piel hacían sus mantos los enoo -tal vez pichones de gaviotas blancas comunes- $\mathrm{y}<$ oripogre $>$ sería amarapawa $=$ "pieza de vestido hecha de guanaco, como una capa, o frontal, o polainas, etc.».

\section{Grupo D: no sugestivas, aunque no excluyentes:}

- $\quad<$ Castemme>: la más grande y austral de las Islas de los Pingüinos -actual Santa Magdalena. Probablemente sea un término compuesto.

- $\quad<$ Talcke>: la más pequeña y boreal de las dos islas.

- $\quad<$ Karay $>$ : tierra de los $<$ Kemenetes $>$.

- $\quad<$ Karamai $>$ : tierra de los $<$ Kennekas $>$.

- $\quad<$ Talche $>$ avestruz. Sólo hallamos un animal de nombre semejante: <yachala $>=$ "perro» (Beauvoir, 1998: 16). Además, los avestruces habrían sido desconocidos en Tierra del Fuego, obviamente, no en la península de Brunswick, cerca de la isla en donde fueron asesinados los enoo.

- A título informativo, destacamos que, aunque creía que los enoo eran alacalufes, Lehmann-Nitsche (2000: 20) comparaba dos vocablos de su lengua con otras dos del yamana-hasha:

- $\quad<$ Enoo $>$ con $<$ inu $>=$ "dirección hacia el oeste», ya visto, y no viable por ser $<$ Enoo $>$ claramente el gentilicio de la parcialidad, que dudo que se llamara «occidental» a sí misma.

- <Kemenites> con <Samakanika>, nombre yamana de la isla L'Hermitte.

Semejanzas del vocabulario de los enoo con otras lenguas aborígenes de la región 
1. Lenguas alacalufes. Los investigadores que nos antecedieron han hallado escasas semejanzas:

a. Lehmann-Nitsche (2000: 20-21) compara <opörkilh> = "piel de guanaco» según Fenton en Hyades y Deniker en 1891 y <opörjal>= «manto, piel» según Skottbserg en 1913, con <oripogre> $y$ $<$ compogre $>$.

b. Clairis (Viegas Barros, 2005: 68) supone que <Enoo> fue mal oído por Van Noort y que sería la palabra xeno $=$ «itoma! $»^{20}$.

c. Viegas Barros (1999: 3) asimila el comienzo <Com-> de $<$ Compogre>= "pingüino» con el Qawasqar del Norte-una lengua alacaluf-, <qjone $>=$ «variedad de pingüino»; compara el zoónimo $<$ cassoni con el Qawasqar Central <halchun>= "ciervo»" ${ }^{21}$ y el etnónimo <Kemenetes $>$ con la palabra del Qawasqar Tawoqser [xeméra] $=$ «extranjero».

Desde que las semejanzas lingüísticas son tan escasas, creo que el argumento más importante para identificar a los enoo con los alacalufes no es lingüístico, sino geográfico y, en menor medida, etnológico.

Por el contrario, la evidencia de que eran yámana es más bien lingüística, lo que se evidencia principalmente en el autónimo $<$ Enoo $>$ y el topónimo <Cos $\sqrt{i}>$, respectivamente, creemos, $<$ ona $>/<$ won $>=$ "hombres» y xaušilkuši= «(mi) Tierra» en lengua yamana. Claro que no podemos negar -ni afirmamos- la posibilidad de que los enoo fueran un grupo mixto yamana-alacalufe, en tal caso con amplio predominio de los primeros.

2. Lengua mapuche o mapudzungun: Lehmann-Nitsche (2000: 20) asocia al topónimo <Talcke> con el de la isla de Talca, atribuyéndolo al mapudzungun con significado de "trueno»-que es $<$ tralka>. Asociación que no creemos viable.

3. Lenguas tehuelches y onas:

a. (Adelung y Vater, 1812, III: 393) asimilan <Kenneka> con el vocablo "de la Patagonia austral», <kunny>= "gente», evidentemente tomado de <cunnee > = "gente», de Falkner (1974: 176), que, como nota Lehmann-Nitsche (2002: 20), corresponde a <kenə>= "gente» en gënëna a iájich.

20. Como Viegas Barros, creemos poco viable la comparación.

21. La propuesta de Viegas Barros resulta tanto más meritoria en cuanto se guía por las transcripciones e interpretaciones de Cooper (1917: 115), quien, con dudas, traduce <cassoni> como «guanaco (?)». Recordemos que en el texto francés de Van Noort (1602: 14 y 15 , traducción propia) se lee con respecto a <cassoni>: «creemos que se trata de ciervos». 
b. Cooper (1917: 115), seguido por Lehmann-Nitsche (2002: 20): <Kenneka> sería similar a <Kenenica>= "onas occidentales» en lengua shelknam.

c. Viegas Barros (2001: 2):

- $\quad$ concuerda con Cooper sobre el gentilicio <Kenneka>, agregando las palabras del shelknam chan nèné-qà = "ser del oeste», $k$-nèné$q r=$ «del oeste»;

- $\quad$ compara $<$ Koin $>$ : nombre de una tierra de gigantes, con la palabra del shelknam chan $k(w)$ 'ójin= "cordillera», y topónimo del oeste de la Isla Grande de Tierra del Fuego;

- $\quad<$ Castemme>: la isla más grande, con el sintagma aónikenk kaš te:m= «tierra dentro de»;

- <Talcke>: la isla pequeña, con el aóniken áish t'alk'e= "chico»;

- $\quad$ el comienzo <Ori-> de <Oripegre $>=$ «manto de pieles cosidas de otro pájaro», con el aóniken áish o’(e)r= "avutarda»;

- $\quad$ el comienzo $<$ Kar-> del gentilicio <Karaikes $>$,y de los topónimos $<$ Karai $>$ y<Karamai $>$, con el comienzo de nombres de lugar en shelknam chan, e.g. kár jé'i= "río Cullen", q'àr hàrs còwn= «nombre de un cerro»;

- $\quad$ el final <-aikes> del (presunto) gentilicio <Karaikes> con el aóniken áish 'ajk'en= "paradero, lugar donde se acampa»;

- $\quad$ el final <-ai> de los topónimos <Karai $>$ y <Karamai>, con la posposición del aóniken áish kaj, 'a = «a, en»;

- $\quad$ en otro trabajo (2005: 68), supone que el gentilicio <Enoo> se relaciona con el protochon <enwo >= «en frente de, al lado de», y da como ejemplo el topónimo shelknam inuq $(n)=$ «lugar lejano tras la cordillera».

d. Por mi parte, he realizado comparaciones propias (Williams, 2012 y 2013):

- $\quad<$ Castemme>: la mayor de las islas Pingüino, e.g. shelknam $<k a s ̌ t e>/<k a s ̌ t a>=$ "pingüino» (Tonelli, 1926, parte segunda: Glosario, apartado «Animali»); 
- $\quad$ gentilicio <karaike>, e.g. topónimo <Karwinká>: nombre shelknam de la isla grande de Tierra del Fuego, y etnónimo <kuyeká $>=$ autónimo de los onas del norte;

- <Coffoni>: "conjeturamos que se trata de ciervos" (Van Noort), e.g. los hipotéticos sintagmas <koškó-jouen>= "guanaco/animal con cuernos», y <koškó-oni>= "guanaco joven con cuernos", del shelknam chan <koshkó>/<kothskó>= «cuerno» y <yowen/ youn $>=$ "guanaco, animal» (Beauvoir, 1998: 133) u <oni $>=$ "guanaco joven» (Tonelli, 1926).

Así, la propuesta de Viegas Barros de que los vocablos incluyeran algunas palabras chon no puede ser descartada.

Pero aunque dicho autor esté en lo cierto, opino que la base de la lengua era yamana, como lo demuestran el autónimo <Enoo $>$ y el topónimo $<$ Cos $\sqrt{1}$, nombre de la tierra que habitaban, el gentilicio <Tirimemen $>$ y el topónimo $<$ Koin $>$, y en menor grado otras palabras que hemos analizado.

Además, puede objetarse que $<$ Koin $>$ parece realmente una palabra yamana-e.g. los famosos $<$ Coin-men $>-$ y en consecuencia no sería chon. En cuanto a la postulada relación entre el autónimo $<$ Enoo $>$ y el protochon "enwo, creemos que antropológicamente no es concebible que una cultura de las llamadas primitivas se auto-colocara enfrente o al lado de algo: dijimos que eran el centro de su mundo, los «Hombres»: en su lengua, los yamana, o los $<w o n>\mid<$ ona $>$. Tampoco puede descartarse una mezcla de los tres idiomas -yamana, alacaluf y chon-pero siempre con prevalencia del primero.

\section{Los huemules (siglo XIX): ¿descendientes de los enoo?}

Hubo en la zona en estudio una tribu de características mixtas entre pámpidos y fuéguidos (Parker King y Fitz Roy, 1839, II: 132-141, 144 y 223-227, traducción propia). Fitz Roy los contactó en 1832 y los llamó huemules:

- Eran unas cien personas.

- Vivían en la actual Isla Riesco, entre los senos de Otway y Skyring, separados del territorio aónikenk por el actual canal Fitz Roy.

- Aspecto y hábitos mixtos de patagones y fueguinos: "[...] raza similar, pero superior, a la de los fueguinos [...] más fuertes, más gallardos, más vivaces y activos [...] mejor formados y de expresión menos mañosa». Los identificaba con una rama de los yacana 
que Falkner ubicaba de ambos lados del estrecho, pero que Fitz Roy asociaba a los onas, según se deduce de sus escritos (Parker King y Fitz Roy, 1839, II: 138).

- Rostros pintados de rojo, azul y negro. Algunos con una piel sobre los hombros, otros solo cubiertos con pintura.

- Bienes semejantes a los de los fueguinos: pieles, flechas, lanzas, chozas, etc. Especialmente, pieles y cuernos de huemul.

- Poseían algunas canoas, pero no caballos. Cazaban huemules y guanacos con perros. Usaban trampas de huesos de ballena. Portaban garrotes.

- Muy independientes, no servían «a ningún señor» ni eran capturados con facilidad por los tehuelches.
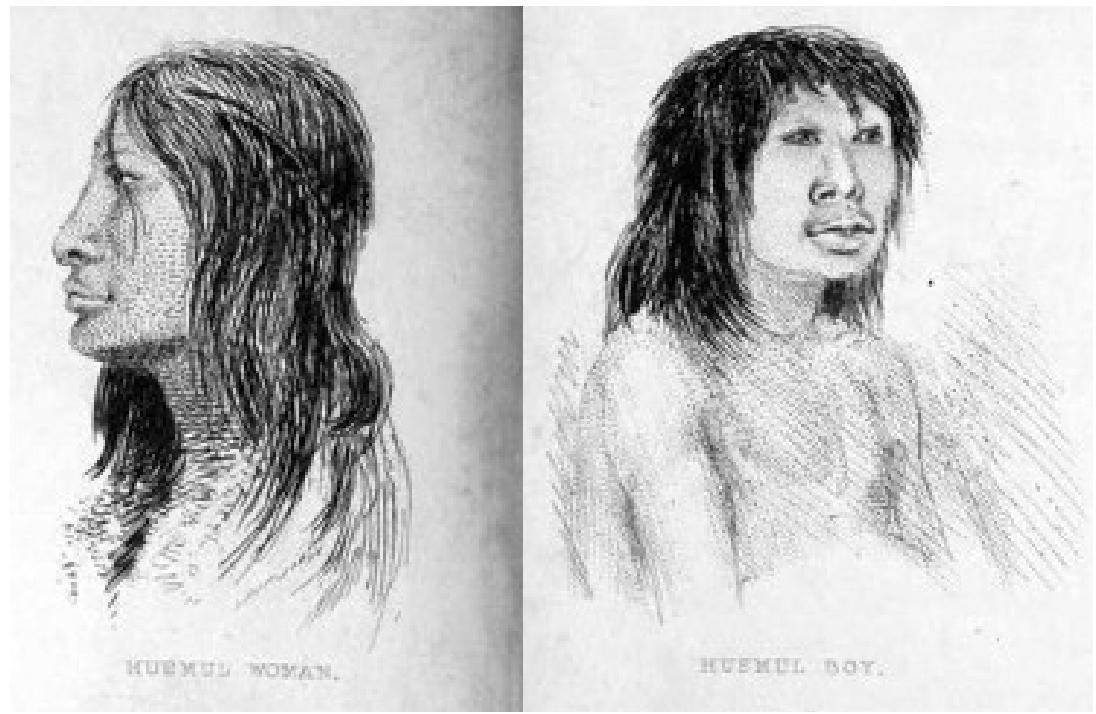

FIGS. 4 Y 5. Huemules: dibujos de una mujer (izquierda) y de un niño (Parker King y Fitz Roy, 1839: sig. a 141).

De forma que los huemules de 1839, parcialidad aparentemente mixta fueguino-chon, habitaban a escasos $50 \mathrm{~km}$ de la Isla de Santa Marta, donde en 1599 fueran aniquilados los enoo, en mi opinión una etnia yamana, pre-yamana, o mixta yamana-chon ${ }^{22}$. Ello abre la posibilidad de 
que los primeros fueran descendientes de los segundos, y no, como se ha supuesto por su localización, una etnia alacaluf-chon ${ }^{23}$, aunque no puede descartarse un pleomorfismo genético y cultural de las tres etnias.

\section{Conclusiones}

Las características físicas, hábitos y zona en que fueron hallados los <Enoo> permiten identificarlos más como fuéguidos (clasificación de Imbelloni, 1938 y 1957) que como chon. Su localización y escasísimas semejanzas lingüísticas llevaron a muchos investigadores a creer que eran alacalufes, o una etnia mixta alacalufe-chon. Solo Gusinde (1951: 79) -sin justificarlo- sugiere que pudieron ser yamanas.

En opinión del autor, cuatro de sus vocablos son claramente yamana $-<$ Enoo $>$, <Kossi $>$, <Tirimenen $>$ y $<$ Koin $>$. Especialmente los dos primeros, el autónimo y el nombre de su tierra, comparables con los vocablos yamana <ona>/<won> y kuši, respectivamente: «(el/los) Hombre(s)» y "(mi) Tierra», constituyen evidencias con gran peso antropológico y lingüístico. Los otros dos corresponderían al gentilicio que los yamana aplicaban a los háush, <Italum ona $>$, y a la tierra en que habitaban, <Koin $>$, que parece la misma palabra que el primer término del gentilicio yamana $<$ Coin-men > del siglo XIX.

¿Qué hacía una tribu yamana en territorio históricamente alacaluf? Tal vez veraneaban allí -demostrando mayor movilidad estacional de la que se les ha atribuido- o su territorio era más extenso que lo que lo sería tres siglos más tarde. Esto pondría en tela de juicio las rígidas atribuciones territoriales de parte de muchos investigadores, frecuentemente clasificando grupos humanos según el territorio que ocupaban.

Además, el testimonio de Van Noort (1599) sería el primero documentando el contacto de los yamana, o pre-yamanas, con europeos, veinticinco años anterior al viaje de Schapenham (1624), considerado hasta ahora el contacto más antiguo. Añadiendo el escrito de De Weert, el de Schapenham sería el tercer documento sobre dicho contacto.

En cuanto a los huemules, tribu mixta fueguino-chon hallada en el siglo XIX en la Isla Riesco, a unos cincuenta kilómetros de la Isla Santa Marta, han sido identificados con los guáicaros, etnia alacaluf-chon de semejante ubicación geográfica. ¿Serían, en cambio, descendientes de los

recolectora en invierno, que habitaba cerca de la Bahía Slogget, sobre la que fuera informado Thomas Bridges, podría ser otro ejemplo de pleomorfismo racial y cultural yamana-chon. 23. Sí lo eran en cambio los guáicaros, según demostraran Casamiquela (Viegas Barros, 2001) y Viegas Barros (2001: 4-10). Habitaron la Isla Riesco, como los huemules, con quienes se los asocia, y la península de Brunswick, zonas muy cercanas a aquella en que fueron hallados los enoo. 
sobrevivientes de los enoo? ¿Tal vez los nativos avistados por Van Noort en la península de Brunswick?

En tal caso, no serían un grupo chon-alacaluf, sino yamana-chon, o una parcialidad mixta de las tres etnias. El alejamiento de las costas, internándose tierra adentro hasta la isla Riesco, podría explicarse como consecuencia de la matanza de 1599.

Hasta el momento y hasta donde sé, todos los trabajos sobre los enoo han sido teóricos. Faltan trabajos arqueológicos. No sería difícil identificar la cueva de los enoo, buscando sus restos, para obtener más conclusiones, incluso análisis genéticos, y compararlos con los de los yamana. Incluso, con los restos de los huemules, si fueran hallados, y los de estos con los de los guáicaros. Tareas para el futuro...

Por lo pronto, estos resultados son una clara demostración de que resulta muy difícil clasificar a los seres humanos solo por sus características somáticas y aún culturales. Los yamana y los alacalufes tenían mucho de ambas en común. El intercambio cultural y genético era constante entre ellos, y aún con grupos chon como los onas, y en menor grado, los tehuelches. También demuestran la posibilidad de variabilidad de la ubicación geográfica de los grupos humanos a lo largo de los siglos. Lo que nos lleva a apoyar el actual relativo descrédito de las clasificaciones étnicas y materialistas de los distintos grupos humanos en épocas pasadas.

Sin embargo, todo grupo humano se ha clasificado a sí mismo y ha clasificado a los demás, en todas las épocas. Dijimos que los yamana son solo un ejemplo de etnocentrismo. Lo propio parece haber ocurrido con los enoo, que se auto-denominaron "[los] hombres», llamaron «mi tierra» a su país, y "hombres o seres del este» a los háush/mánekenk. Ello en una lengua que impresiona, muy relacionada con el yamana-hasha, al menos en su sustrato principal -aunque posiblemente tuviera una importante carga de préstamos chon, menos probablemente alacalufes. Desde la auto-referencia, los hombres se han referido siempre a otros, calificándolos para clasificarlos.

En tal sentido, las clasificaciones de grupos humanos basadas en la auto-referencia serían correctas.

Esta perspectiva contribuye a objetivar la diversidad cultural y lingüística que enriquece nuestro común patrimonio humano. 


\section{Referencias bibliográficas}

Adelung, J.C. y Severin Vater, J. (1812). Mithridates: oder allgemeine Sprachenkunde, 3, Berlin.

Aguilera, Ó.E. (2000). En torno a la estructura fonológica del yagán. Fonología de la palabra. Universidad de Chile, Facultad de Ciencias Sociales. Onomazein, revista semestral de lingüística, filología y traducción. Vicerrectoría de Comunicaciones y Asuntos Sociales, Pontificia Univeridad Católica de Chile, 5. Santiago de Chile: 233-241.

Beauvoir, J.M. (1998). Los shelknam, indígenas de la Tierra del Fuego. Sus tradiciones, costumbres y lengua. Buenos Aires: Zagier \& Urruty.

Bove, G. (2005). Expedición a la Patagonia. Un viaje a las tierras y mares australes. Buenos Aires: Ediciones Continente.

Bridges, E.L. (2005). El último confín de la tierra. Buenos Aires: Editorial Sudamericana.

Bridges, T. (1987). Yamana-English Dictionary. A dictionary of the speech of Tierra del Fuego. Printed by Missiondruckerei St. Gabriel, Mödling, Austria, 1933, for private circulation. Buenos Aires: Ediciones Shanamiim.

Bridges, T. (2001). Los indios del último confín. Sus escritos para la South American Missionary Society. Buenos Aires: Zagier \& Urruty Publications.

Brinton, D. (1892). Studies in South American Native Languages (VII): The Hongote language and the Patagonian dialects. Proceedings of the American Philosophical Society, 30 .

Bry, T. de (1590-1634). IX Historia Americae Sive Novi Orbis 1590-1634. Collectiones peregrinatiorum in Indiam orientalem et Indiam occidentalem, XIII partibus comprehenso a Theodoro, Joan-Theodoro de Bry, et a Matheo Merian publicatae. Frankfurt.

Canclini, A. (2007). The Fuegian Indians. Their life, habits and history. Buenos Aires: Dunken.

Casamiquela, R. (1973). Alacalufes, canoeros occidentales y pueblos marginales o metamórficos. Relaciones de la Sociedad Argentina de Antropología, nueva serie, VII: 125143.

Coiazzi, A. (1999). The Indians of the Fueguino Archipielago. Punta Arenas: Ateli.

Cooper, J.M. (1917). Analytical and Critical Bibliography of the Tribes of tierra del Fuego and Adjacent Territory. Bureau of American Ethnology, 63. Washington: Government Printing Office.

Chapman, A. (2010). European encounters with the Yamana people of Cape Horn, before and after Darwin. Cambridge: Cambridge University Press.

Dabene, R. (2009). Un viaje a la Tierra del Fuego. Buenos Aires: Albatros.

Drukker, J.W. y Tassenaar, V. (2000). Shrinking Dutchmen in a growing economy: the early industrial growth paradox in the Netherlands. Jahrbuch für Wirtschaftsgeschichtel Economic History Yearbook, 41(1): 77-94. 
Fabre, A. (2005). Diccionario etnolingüístico y guía bibliográfica de los pueblos sudamericanos. En http://butler.cc.tut.fi/ fabre/BookInternetVersio/Dic=Yahgan.pdf. Accedido el 24 de junio de 2013.

Falkner, T. (1974). Descripción de la Patagonia y de las partes contiguas de América del Sur. Buenos Aires: Hachete.

Gallez, P.J. (2002). La más antigua descripción de los yámana: Schapenham,1642. Ushuaia: Museo del Fin del Mundo. En http://www.tierradelfuego.org.ar/museo/virtual/yamanaantiguo.htm. Accedido el 24 de junio de 2013.

Gusinde, M. (1951). Los Fueguinos. Hombres Primitivos en la Tierra del Fuego (de investigador a compañero de tribu). Sevilla: Escuela de Estudios Hispanoamericanos.

Hidalgo, J.; Schiappacasse, V.; Niemeyer, H.; Aldunate, C.; y Mege, P. (1996). Etnografía: sociedades indígenas contemporáneas y su ideología. Santiago de Chile: Editorial Andrés Bello.

Kerr, R. (1824). General History and Collection of Voyages and Travels, X, sección II. W. Blackwood y T. Cadell, Eds. Edinburg.

Imbelloni, J. (1938). Tabla clasificatoria de los indios. Regiones biológicas y grupos raciales de América. Buenos Aires: Museo Argentino de Ciencias Naturales. Imprenta y Casa Editora Coni.

Imbelloni, J. (1957). Los grupos raciales aborígenes. Buenos Aires: Facultad de Historia y Letras, Facultades Universitarias del Salvador.

Laet, J. de (1640). L'Histoire du Nouveau Monde ou Description de las Indes Occidentales. Leyde: Bonavenure \& Abraham Elseviers.

La Harppe, J.F. de (1820). Abrégé de l'Histoire Génerale des voyages, 17. Paris: Étienne Ledoux Librairie.

Latcham, R.E. (1928). La prehistoria chilena. Santiago de Chile: Universo.

Lehmann-Nitsche, R. (2002). El Grupo Lingüístico Alakaluf. Revista del Museo de La Plata. Universidad Nacional de La Plata, XXV(3,I). Buenos Aires: Imprenta y Casa Editora Coni.

Lévy-Bruhl, Lucien (1986). El alma primitiva. Barcelona: Planeta-Agostini.

Lothrop, S.K. (2002). The Indians of Tierra del Fuego. An account of the Ona, Yahgan, Alacaluf and Haush Natives of the Fuegian Archipielago. New York: Museum of the American Heye Foundation.

Llarás Samitier, M. (1967). El grupo chono o wayteka y los demás pueblos Fuegopatagonia. Runa. Archivo para las Ciencias del Hombre.

Martínez-Carrión, J.M. (2011). La talla de los europeos desde 1700: tendencias, ciclos y desigualdad. Documentos de trabajo de la Soc. Española de Estudios Agrarios. En http:// repositori.uji.es/xmlui/bitstream/handle/10234/22980/DT-1106.pdf? sequence=1. Accedido el 27 de abril de 2014.

Martinic Berós, M. (1989). Los canoeros de la Patagonia meridional. Población histórica y distribución geográfica (siglos XIX y XX). El fin de una etnia. Journal de la Societé des Americanistes, 75: 35-61. 
Martinic Berós, M. (2012). Los holandeses en las Islas de los Pingüinos. Magallanía, 40(2). En http://www.scielo.cl/scielo.php?pid=S0718-22442012000200001\&script=sci_arttext. Accedido el 27 de abril de 2014.

Parker King, P. y Fitz Roy, R. (1839). Narrative of the surveying voyages of His Majesty's Ships Adventure and Beagle between the years 1826 and 1836, describing their examination of the southern shores of South America, and the Beagle's circumnavigation of the globe, 2, Appendix. London: Henry Colburn.

Prior, S. (1844). All the voyages round the world, from the first by Magellan, in 1520, to that of Freycinet, in 1820-now first collected by Capt. Samuel Prior. New York: William H. Coyler.

Tonelli, A. (1926). Grammatica e Glossario della lingua degli Ona-šelknam della Terra del Fuoco. Contributi Scientifici delle Missione Salesiane del venerabile Don Bosco. Torino: Societá Editrice Internazionale. En http://ebooks.gutenberg.us/wordtheque/ it/00006 it.txt. Accedido el 28 deabril de 2014.

Van Noort, O. (1602). Description du penible voyage faict autor de l'Universe du globe terrestre par Sr. Olivier du Noort d'Utrecht, general de quatre navires. Amsterdam: Comille Claefsz.

Vernazani, M. (2007). Observaciones extraídas de los viajes que al Estrecho de Magallanes han ejecutado en diferentes años los almirantes y capitanes Olivares de Noort, Simón de Cordes, Jorge Spilberg, Francisco Drake, Juan Childley, Tomás Candish, Juan Narborough. En Viajes por las costas de la Patagonia y los campos de Buenos Aires. Informes, diarios y cartas de viajeros (s. XVIII). P. de Angelis. Buenos Aires: Ediciones Continente.

Viegas Barros, J.P. (2001). Enoo y guáicaro: dos entidades lingüísticas problemáticas de la Patagonia austral. Actas del Tercer Congreso Argentino de Americanistas. Buenos Aires, II, 1999, Sociedad Argentina de Americanistas: 485-499. Citamos los números de página del archivo PDF enviado por el autor (com. pers, 28 de diciembre de 2013).

Viegas Barros, J.P. (2005). Voces en el viento. Raíces lingüísticas de la Patagonia. Buenos Aires: Mondragón.

Williams, D. (2012). Una aproximación a la identificación étnico-lingüística de los Enoo, hallados en el Estrecho de Magallanes por la expedición Van Noort (1599). Ponencia presentada en el XII Congreso de la SAL (Sociedad Argentina de Lingüística, Potrero de los Funes, San Luis, Argentina, 27-30 de marzo. No publicada.

Williams, D. (2013). Hacia la identificación étnico-lingüística de la tribu Enoo, exterminada en el Estrecho de Magallanes por la expedición Van Noort (1599). Ponencia presentada en el IX Congreso de Historia Social y Política de la Patagonia Argentino-Chilena, Trevelin, Chubut, Argentina, 6-8 de octubre. No publicada. 
